\title{
Do Phytotoxic Compounds in Soils after Scale-infested Cycas micronesica Litter Deposits Explain Reduced Plant Growth?
}

\author{
Thomas E. Marler ${ }^{1}$ and Nirmala Dongol \\ College of Natural and Applied Sciences, University of Guam, UOG Station, \\ Mangilao, Guam 96923
}

Additional index words. allelopathy, Aulacaspis yasumatsui, Cycas micronesica, germination, Guam, phytotoxins

\begin{abstract}
We used activated charcoal methods to test for the presence of phytotoxic substances in soils that had received inputs of decomposing Cycas micronesica K.D. Hill leaves and stems that were heavily infested with the armored scale Aulacaspis yasumatsui Takagi. Velocity of Momordica charantia Descourt. and Carica papaya L. seedling emergence was increased by the addition of charcoal to these soils. Furthermore, M. charantia and $C$. papaya seedling height and dry weight were among the response variables that were increased by the addition of charcoal. Legacy effects of scale-infested $C$. micronesica plant litter deposited in these soils resulted in phytotoxic compounds that inhibited seedling emergence and plant growth. Scale-infested Cycas leaves should not be used as mulch or in compost until phytotoxic causal mechanisms are more fully understood.
\end{abstract}

Aulacaspis yasumatsui Takagi invaded Guam in 2003 (Marler and Muniappan, 2006). At that time, Cycas micronesica (Fig. 1A) was the most dominant tree species in natural forests (Donnegan et al., 2004). Furthermore, this native cycad species and the internationally popular Cycas revoluta Thunb. were dominant in the residential and commercial landscape at the time (Marler, 2012). The armored scale killed landscape trees by the end of 2005 unless chemical protection was employed. Furthermore, the pest was largely responsible for killing more than $90 \%$ of the C. micronesica plants in Guam's forests (Marler and Lawrence, 2012).

Loss of host species following invasions of specialist phytophagous insects is occurring with greater frequency. Meaningful studies are needed to evaluate how the systems change following those losses, a need that is heightened when the host species is a dominant species (Marler and Lawrence, 2013). When these same insects become horticultural pests, increases in costs for pest protection and decreases in aesthetic value of the host species may occur. Therefore, some invasive insect species can eliminate the appeal of growing their host species in home gardens, commercial orchards, or agroforestry settings.

The initial pulse of scale-infested $C$. micronesica leaf litter was substantial shortly after the scale immigrated into new habitats (Fig. 1B). Thereafter, continuing inputs of

Received for publication 15 July 2013. Accepted for publication 10 Oct. 2013.

Support provided by U.S. Forest Service Project No. 06-DG-11052021-206 and No. 09-DG-11052021-173. ${ }^{1}$ To whom reprint requests should be addressed; e-mail tmarler@uguam.uog.edu. dead leaf and stem tissue to the forest floor opened up canopy gaps as the plants were killed (Fig. 1C). Root and stem decomposition then increased biochemical inputs to the soil matrix from dead cycad tissue. Unlike other canopy gaps in Guam, the open soil surfaces often failed to recruit new plants from the seed bank or immigration (Fig. 1C). These barren sites had received no pesticide applications, so observations indicated a phytotoxic chemical legacy may be causal. However, no effort has been made to understand this phenomenon. If scale-infested cycad litter is validated as a source of phytotoxic compounds, horticulturists would become more informed for making management decisions in areas infested with $A$. yasumatsui.

The objective of our study was to examine if a chemical legacy effect is linked with the lack of seedling growth in soils with a history of litter from recently killed $C$. micronesica trees. We used standard allelopathy-based research protocols using activated charcoal as a substance that adsorbs organic compounds in combination with fertilization to correct for any influence of the activated charcoal on soil nutrient availability (Inderjit and Callaway, 2003; Scharfy et al., 2011). We selected papaya (Carica papaya) and bitter melon (Momordica charantia) for the bioassays for two reasons. First, these two naturalized pioneer species are among the most rapid to emerge whenever canopy gaps occur in Guam's limestone forests. Second, improved genotypes of these two species are grown in home gardens and commercial farms in Guam and all other Micronesian islands. Our results should inform management decisions when cycads are used in horticultural and agroforestry settings and $A$. yasumatsui infestations are problematic.
Soil was collected from the top $20 \mathrm{~cm}$ in a habitat that formerly supported a high density C. micronesica population. Aulacaspis yasumatsui invaded the habitat $\approx 3$ years before collection of the soil, and $\approx 90 \%$ of the $C$. micronesica plants had been killed at the time of soil collection. Therefore, large amounts of scale-infested cycad organs had been deposited into the soils during the previous $\approx 2.5$ years. The soils were Shioya sand (Carbonatic, isohyperthermic Typic Ustipsamments; Young 1988).

We collected the soil from eight locations in the habitat, and kept a separate sample for analysis from each of the locations. Total $\mathrm{N}$ was $7.0 \pm 0.4 \mathrm{mg} \cdot \mathrm{g}^{-1}$, available $\mathrm{P}$ was $8.31 \pm$ $0.45 \mathrm{mg} \cdot \mathrm{kg}^{-1}$ (weak Bray), exchangeable $\mathrm{K}$ was $30.73 \pm 1.58 \mathrm{mg} \cdot \mathrm{kg}^{-1}$, total C was $158.2 \pm$ $1.9 \mathrm{mg} \cdot \mathrm{g}^{-1}$, and organic matter was $24 \pm$ $1 \mathrm{mg} \cdot \mathrm{g}^{-1}$ (mean $\pm \mathrm{SE}, n=8$ ).

A $1 \mathrm{~L}$ sample of soil was removed from the bulk soil and inspected for large seeds. The only seeds that we found then removed were Pandanus tectorius Parkinson ex Zucc. seeds. To determine if viable papaya or bitter melon seeds were in the harvested soil, we spread the $1 \mathrm{~L}$ sample in a tray to $3 \mathrm{~cm}$ depth, placed the tray under $50 \%$ shade, and maintained moist soil for 4 weeks. Only five Passiflora suberosa L. seedlings emerged from the soil.

Half of the bulk soil was treated with $2 \%$ (by volume) activated charcoal (Penn-Plax, Hauppauge, NY) to bind to any organic compounds that could present phytotoxic properties (Inderjit and Callaway, 2003). For germination and growth tests, fruits were collected from wild plants in habitat. The papaya fruits were collected and seeds cleaned on 7 Sept. 2010; the study was initiated on 27 Sept. 2010, and final measurements were conducted on 16 Nov. 2010. Bitter melon fruits were harvested and seeds cleaned on 9 Oct. 2010; then the experiment was initiated on 19 Jan. 2011 and ended on 22 Feb. 2011 Extracted seeds were allowed to dry in ambient conditions before sowing.

The seeds were planted in $0.625-\mathrm{L}$ pots containing one of the two soil treatments, with each pot considered one replication containing five seeds. The containers $(n=8)$ were distributed on the bench in an outdoor nursery randomly for each experiment. The seedlings were grown under full sun conditions, and irrigated as needed. Activated charcoal has affinity for some nutrient forms (Cheremisinoff and Ellerbusch, 1978), so correcting for plant nutrition was required to ensure observed adverse responses could be attributed to phytotoxic compounds rather than plant nutrition. Therefore, containers were fertilized weekly with $25 \mathrm{~mL}$ of complete fertilizer solution (Miracle-Gro; The Scotts Company, Marysville, $\mathrm{OH}$ ) providing $7.5 \mathrm{~mm} \mathrm{~N}$.

The number of emerged seedlings in each container was recorded daily for the duration of the study. The largest seedling was retained at $21 \mathrm{~d}$ when the remainder of seedlings were removed from each container. Daily 
observation for further seedling emergence continued thereafter, with any newly emerged seedlings removed after recording emergence date. Ending plant height and leaf number were recorded, then plants were bare rooted, separated into root and stem + leaf sections, and dried to constant weight at $70{ }^{\circ} \mathrm{C}$ to determine final dry weight.

Final emergence was defined as the cumulative number of seedlings that emerged as a proportion of seeds planted. The minimum time to emergence was defined as the number of days from sowing to emergence of the first seedling in each replication. The emergence velocity index was a modification of the germination test defined by Woodstock
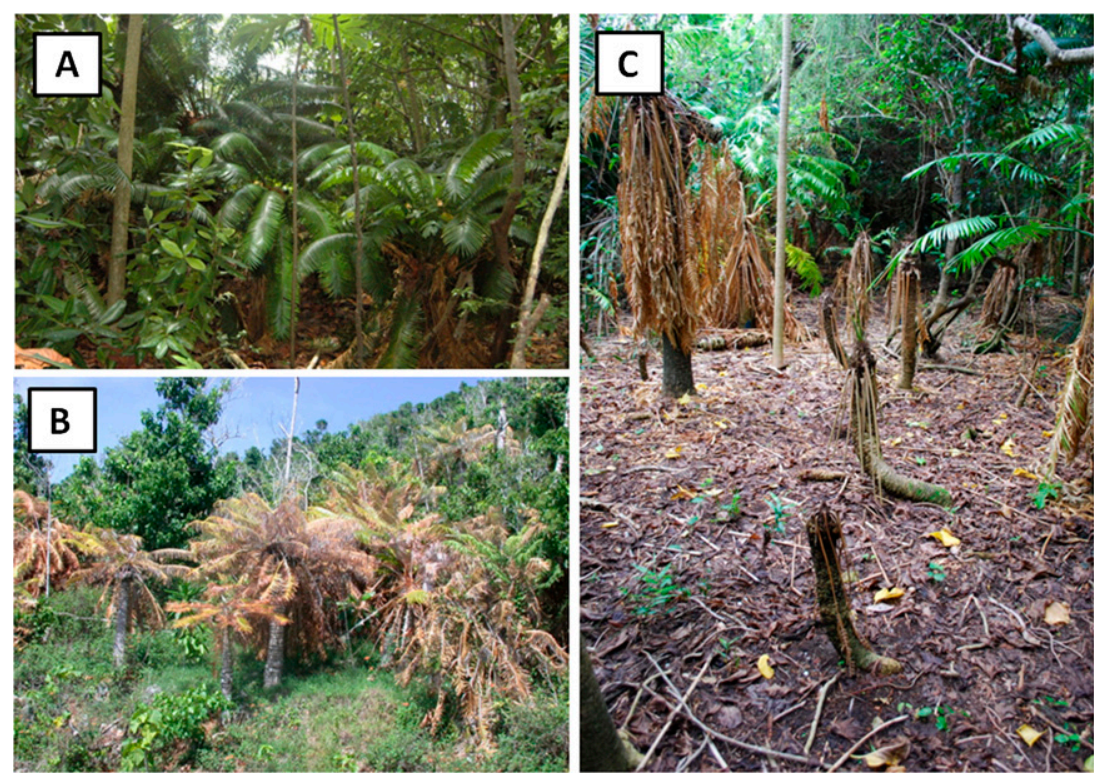

Fig. 1. Cycas micronesica was the dominant tree species in Guam before the 2003 invasion of Aulacaspis yasumatsui. (A) Typical forest habitat before the invasion. (B) The first pulse of scale-infested dead leaves immediately following initial A. yasumatsui infestation was substantial, and started several years of scale-infested litter inputs that ended with plant death. (C) A site after 3 years of $A$. yasumatsui damage showing plant mortality and resultant barren soils.

Table 1. Emergence and growth traits of Momordica charantia and Carica papaya seedlings sown in soils that received 2.5 years of scale-infested Cycas micronesica litter, or these soils amended with $2 \%$ activated charcoal. Mean $\pm \mathrm{SE}, n=8$.

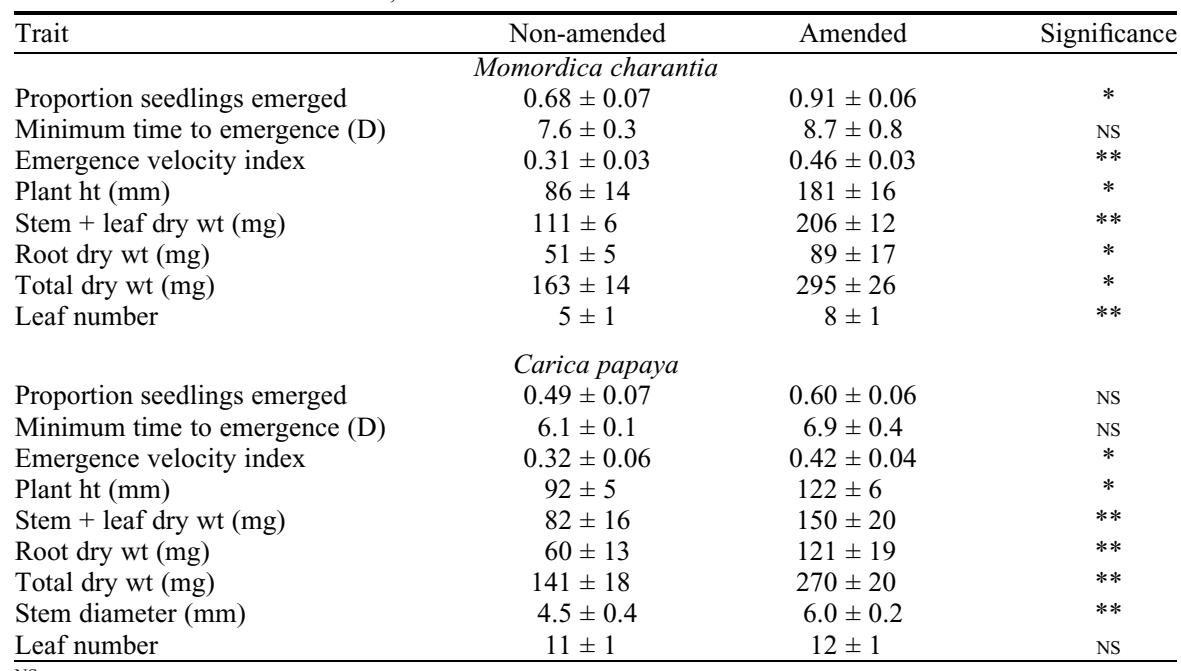

NS, $*, * *$ Nonsignificant, $P \leq 0.05$, or $P \leq 0.01$, respectively. velocity index in amended soil was $47 \%$ greater than that in non-amended soil. Minimum time to emergence was not influenced by soil amendment. Amending the soil with activated charcoal increased root dry weight, stem + leaf dry weight, total plant dry weight, and leaf number in similar magnitudes (Table 1). Therefore, no substantial change in root/shoot allocation was detected. Plant height was increased more so than the other significant response variables, exhibiting a $110 \%$ increase in response to charcoal amendment.

Amending the soil did not influence cumulative emergence of papaya seedlings or the minimum time to emergence, but increased emergence velocity index (Table 1 ). Moreover, papaya seedling growth was increased by amending the soil with activated charcoal. Root dry weight, stem + leaf dry weight, and total plant dry weight were increased by soil amendment 1.8 - to 2.0 -fold above that of non-amended soil (Table 1). Plant height in amended soil was 33\% greater than that in non-amended soil. Papaya leaf number was not influenced by soil amendment.

\section{Discussion}

Our use of activated charcoal to ameliorate Guam's soils in receipt of 2.5 years of scale-infested $C$. micronesica litter showed that these soils indeed contained phytotoxic compounds that inhibited plant growth. We have not attempted to identify the chemicals or determine their origin. Perhaps the phytotoxic compounds originated in the extensive surface layer of A. yasumatsui carcasses affixed to the dead plant organs. To our knowledge, there have been no reports indicating chemical residues from dead armored scale carcasses and retained exuviae may contain phytotoxic chemicals. Alternatively, the phytotoxic compounds may have originated via de novo biosynthesis of induced secondary metabolites by the dying plants in response to the dense scale infestations. Herbivory-induced stimulation of phytotoxic compound(s) by a plant and the deposition of those compounds into the soil have been reported for the heavily studied Centaurea maculosa Lam. (Callaway et al., 1999; Thelen et al., 2005). Although further work is needed to identify putative chemicals and determine their bioactive concentrations in our case study, our results have completed the more important first step of verifying that phytotoxic compounds indeed persist in these soils (Inderjit and Callaway, 2003; Tharayil, 2009).

The relevance of phytotoxic compounds in invasion biology has been extensively discussed in relation to the success of invasive plant species. Some highly invasive plants are allelopathic, and one proposed mechanism for why they become aggressive in their invaded range is because their particular phytotoxic compounds are novel to the native plant members of the communities they invade (Bais et al., 2003; Callaway and Aschehoug, 2000; Fitter, 2003). We have shown that the occurrence of phytotoxic compounds following an invasion is not restricted to invasive 
plant species, and invasive specialist herbivores may invoke the same result following lethal infestations on their host plant species.

Uesugi and Kessler (2013) described increased production of phytotoxic chemicals that improved competitive ability of Solidago altissima L. plants after release from herbivory. Our study illuminates an opposing scenario, where the natural lack of phytophagous insect herbivory of this island endemic tree results in no observable phytotoxic residues, but herbivory of the host by an alien insect elicits a phytotoxic soil chemical legacy.

This study reveals an example of how cascading effects of an invasive insect can negatively affect nonhost species. We suggest that scale-infested Cycas leaves should not be used as mulch or in compost until causal mechanisms of the phytotoxicity are determined or at least until this phenomenon is more fully understood. Moreover, burial or burning of scale-infested Cycas leaves may diminish further dispersal of the scale.

\section{Literature Cited}

Bais, H.P., R. Vepachedu, S. Gilroy, R.M. Callaway, and J.M. Vivanco. 2003. Allelopathy and exotic plants: From genes to invasion. Science 301: 1377-1380.

Callaway, R.M. and E.T. Aschehoug. 2000. Invasive plants versus their new and old neighbors: A mechanism for exotic invasion. Science 290:521-523.

Callaway, R.M., T.H. DeLuca, and W.M. Belliveau. 1999. Biological-control herbivores may increase competitive ability of the noxious weed Centaurea maculosa. Ecology 80:1196-1201.

Cheremisinoff, P.N. and F. Ellerbusch. 1978. Carbon adsorption handbook. Ann Arbor Science Publishers, Ann Arbor, MI.

Donnegan, J.A., S.L. Butler, W. Grabowiecki, B.A. Hiserote, and D. Limtiaco. 2004. Guam's forest resources, 2002. Resource Bulletin PNW-RB243. U.S. Department of Agriculture, Forest Service, Pacific Northwest Research Station, Portland. $32 \mathrm{pp}$.

Fitter, A. 2003. Making allelopathy respectable. Science 301:1337-1338.

Inderjit and R.M. Callaway. 2003. Experimental designs for the study of allelopathy. Plant Soil 256:1-11.

Marler, T.E. 2012. Cycad aulacaspis scale invades the Mariana Islands. Mem. N. Y. Bot. Gard. 106:20-35.

Marler, T.E. and J.H. Lawrence. 2012. Demography of Cycas micronesica on Guam following introduction of the armoured scale Aulacaspis yasumatsui. J. Trop. Ecol. 28:233-242.
Marler, T.E. and J.H. Lawrence. 2013. Canopy and knowledge gaps when invasive alien insects remove foundation species. Commun. Integr. Biol. 6:e223311-e223315.

Marler, T.E. and R. Muniappan. 2006. Pests of Cycas micronesica leaf, stem, and male reproductive tissues with notes on current threat status. Micronesica 39:1-9.

Scharfy, D., A. Funk, H.O. Venterink, and S. Güsewell. 2011. Invasive forbs differ functionally from native graminoids, but are similar to native forbs. New Phytol. 189:818 828.

Tharayil, N. 2009. To survive or slay. Plant Signal. Behav. 4:580-583.

Thelen, G.C., J.M. Vivanco, B. Newingham, W. Good, H.P. Bais, P. Landres, A. Caesar, and R.M. Callaway. 2005. Insect herbivory stimulates allelopathic exudation by an invasive plant and the suppression of natives. Ecol. Lett. 8:209-217.

Uesugi, A. and A. Kessler. 2013. Herbivore exclusion drives the evolution of plant competitiveness via increased allelopathy. New Phytol. 198: 916-924.

Woodstock, L.W. 1976. Seed vigour testing handbook. Assoc. Official Seed Analysis of America NewsLetter 50.

Young, F.J. 1988. Soil Survey of Territory of Guam. United States Department of Agriculture Soil Conservation Service. 